\title{
A SOMBRA E A CRÍTICA: FOTOGRAFIA, LITERATURA, CINEMA
}

Pedro Henrique Trindade Kalil Auad*

\author{
*pedroauad@gmail.com \\ Mestre em Teoria da Literatura pela Faculdade de \\ Letras da UFMG e Doutorando em Teoria da Literatura \\ e Literatura Comparada pela mesma instituição.
}

RESUMO: O presente trabalho parte do texto La Sombra y el Tiempo de Jean-Claude Lemagny e tenta compará-lo não somente a procedimentos fotográficos - que o auto aborda no texto -, como também com a literatura e o cinema. Tentarei demonstrar que alguns pontos abordados no texto de Lemagny também ajudam a iluminar a respeito de outras artes e de certas teorias da literatura e do cinema. Em um primeiro momento, abordarei algumas questões do texto do pensador francês, focalizando o aspecto da luz e sombra e da perda e permanência. Em um segundo momento, tentarei dar exemplos de como em outras artes esses aspectos são tratados. Por fim, compararei a teoria de Lemagny com procedimentos de outras teorias.

PALAVRAS-CHAVE: Fotografia; Cinema; Literatura; Crítica; Teoria.
ABSTRACT: This present work is based on the text by Jean-Claude Lemagny, La Sombra y el Tiempo, and tries to compare it not only photographic procedures - which the author addresses in the text - but with the literature and the cinema. I'Il try to show that some points raised in Lemagny's text also helps to illuminate about other arts and certain literature theory and film theory. At first I'll discuss some questions of the text of the French philosopher, focusing on the aspect of light and shadow, loss and permanence. In a second stage, I'll try to give examples of how these aspects are treated in other arts. Finally, I'Il link the theory of Lemagny with procedures of other theories.

KEYWORDS: Photography, Cinema, Literature, Criticism, Theory. 
1. LEMAGNY. La Sombra y el Tiempo, p. 55. [tradução livre de minha autoria.
In the shadowplay, acting out your own death, knowing no more, As the assassins all grouped in four lines, dancing on the floor, And with cold steel, odour on their bodies made a move to connect, But I could only stare in disbelief as the crowds all left.

"Shadowplay", Joy Division

\section{A SOMBRA E O TEMPO}

O texto La Sombra y El Tiempo gira em torno do problema da especificidade artística da fotografia. Em outras palavras: o que faz da fotografia uma arte? O que ela tem de particular? Como ela escreve a sua própria história? Qual a sua relação com as outras artes pictóricas e o que ela tem de diferente?

O teórico francês Jean-Claude Lemagny começa com uma primeira questão: são todas as fotografias arte? As fotografias da publicidade e do jornalismo são formadas da mesma forma que as fotografias de "grandes artistas"? Jean-Claude se pergunta como a fotografia da publicidade pode ser considerada arte já que está a serviço do comércio. Dessa forma, a fotografia da publicidade se inscreveria somente em um regime estético, e isso não basta para que seja transformada em arte. Diferente, a fotografia do jornalismo poderia entrar no regime artístico, já que, "por definição e desde sua origem, contêm uma preocupação com a verdade".

Ora, a verdade poderia ser muito bem verificada em alguns fotógrafos, estes que aparentemente reproduziriam a realidade mimeticamente simples: um objeto e sua representação. Vendo a realidade dessa forma, a fotografia seria reduzida a um ilusionismo visual. Poder-se-ia dar como exemplo Cartier-Bresson que reproduz eventos do cotidiano, ou a fotógrafa, reconhecida tardiamente e por acaso, Vivian Maier, uma babá que tirava fotos sem a intenção propriamente artística, muito mais como um hobby, e que hoje passa a ocupar lugar em exposições e museus, também poderia fazer parte desse significado da fotografia.

Reproduzir a realidade tal qual ela é: seria essa a vocação da fotografia? A fotografia surge em um momento em que a pintura retornava à exatidão ótica. Coube à fotografia a tarefa de manter o realismo, enquanto a pintura caminhou para outros caminhos, em especial para o abstracionismo. Mas a fotografia não se resume a isso, ou melhor, não é isso: a fotografia não é realista - é o que afirma Lemagny. E não é por distinção entre fotógrafos da "realidade" e os da "fantasia”, um conflito entre Dorothea Lange e Jerry Uelsmann. O realismo fotográfico não seria mais do que uma convenção simplista.

Esse "falso realismo" pode ser percebido quando JeanClaude nos diz do processo fotográfico enquanto arte que pode ser pensada como uma arte fragmentada. Jean-Claude divide em três partes o surgimento e o processo da fotografia: a tomada (o fazer), a seleção de negativos e a cópia ou ampliação. Cada uma dessas partes tem suas particularidades,

EM TESE

BELO HORIZONTE

v. 19

N. 3

SET.-DEZ. 2013

AUAD. A Sombra e a Crítica: fotografia, literatura, cinema

p. $94-108$

Crítica Literária, outras Artes e Mídias 
2. LEMAGNY. La Sombra y el Tiempo, p. 37. [tradução livre de minha autoria].

3. LEMAGNY. La Sombra yel Tiempo, p. 40. [tradução livre de minha autoria]. que não necessariamente são realizadas todas pelo artista que batiza a obra.

A tomada seria a projeção sobre o objeto, de forma objetiva e subjetiva, que toca, sem intermediários, em uma tentativa de representação de um pensamento. Nessa hora o fotógrafo precisa de luz, ela transmite a aparência de toda forma, mas que resulta a luz, "em todas as partes difusa e dispersa, confunde e exclui imediatamente o que transporta" ${ }^{2}$ Ou seja, a tomada não é mais do que uma criação, mas uma criação que também é composição e não realização, não se realiza a imagem, a captura.

Na seleção de negativos, para Lemagny, se escolhe as imagens em ambiguidade profunda do real. Na revelação do negativo haveria imagens como se tivessem surgido de um mundo desconhecido, com aspectos de aparições. A cópia, por sua vez, já é a eleição das aparências - uma aparição. A imagem só aparece com uma dose de luz e químicos - olho e mão realizando o projeto do espírito que começou com a tomada. É nesse momento que surge a experiência sensorial da substancia material da fotografia. Por fim, a fotografia são três ciclos, e nesses ciclos "a imagem se mune de mistério e também de um suplemento de presença. E, depois de pronta, a imagem encarna uma vida já independente de coisa no mundo"3.

No texto de Lemagny fica evidente que tentar definir a fotografia como arte específica por causa do processo fragmentado é insuficiente. Por isso, o pensador francês aborda outras formas que poderiam definir a fotografia como arte. A primeira seria a abordagem da arte como excelência da criação artesanal, mas a fotografia não é simplesmente um ofício da arte. A segunda abordagem considera a fotografia como capaz de produzir obras de beleza. Como pinturas, que existem umas mais bonitas do que outras, existiriam também fotografias mais bonitas do que outras, mas daí a fotografia seria uma arte por exceção. Uma pintura, mesmo que uma má pintura, continuaria sendo uma pintura. A má fotografia deixaria de ser arte? - nos questiona Lemagny.

A terceira abordagem diz respeito à totalidade no espaço e sobre todo o tempo. Esta seria uma abordagem histórica que afirma que a arte existe à medida que há uma história da arte. Dessa forma, a fotografia seria um encadeamento irreversível das maneiras que sucedem por imitação ou conflito. Essas três abordagens parecem insuficientes na visão de Lemagny.

A quarta e última abordagem, a que, para o pensador francês, poderia definir, enfim, a fotografia como arte e sua história, seria a fotografia que questiona a si mesma. Assim, a fotografia seria arte por aquilo que nela escapa à definição. Ou seja, a fotografia seria arte porque ela se autoquestiona, porque é reflexiva em si mesma.

Se arte, a fotografia também seria estilo. "Porque na arte o estilo mima o mundo, não o imitando em suas formas

EM TESE

$$
\text { BELO HORIZONTE }
$$


4. LEMAGNY. La Sombra y el Tiempo, p. 61. [tradução livre de minha autoria].

5. LEMAGNY. La Sombra y el Tiempo, p. 62. [tradução livre de minha autoria].

6. LEMAGNY. La Sombra y el Tiempo, p. 63. [tradução livre de minha autorial. aparentes, e sim em sua maneira de ser, em seu movimento para sua própria perfeição, em sua realização"4. Aqui - para Lemagny - acontece a diferença entre a pintura e a fotografia. Na pintura, o artista capturaria, transformaria e unificaria a natureza, enquanto na fotografia a capturar seria ao estilo "natural" do mundo, mas um estilo que decompõe o mundo, com o artista selecionando facetas que lhe convém. O estilo de um grande fotógrafo é "justaposições de ocasiões escolhidas, localizadas, esperadas com uma constância excepcional. Entre as muitas facetas do mundo, ele só retém aquelas que lhe convém"5.

Aqui há outro ponto que diferenciaria a fotografia de outras artes: se um estilo pode ser cooptado e copiado na pintura ou na literatura, fazendo à maneira de, o fotografo pode, sem pretender, realizar uma fotografia no estilo de outro Dessa forma, Jean-Claude percebe uma oposição radical entre as artes do desenho e a fotografia. "Os desenhos estão completos, e a fotografia é oca. Unidade e diversidade, necessário e facultativo, o adicionado e o presente, engendrado e adotado: tudo as opõe. De maneira que a fotografia não aparece tanto como um caso diminuído da arte mas como seu reflexo invertido" 6 .

Por ser a fotografia um reflexo invertido da arte, JeanClaude acredita que a sociedade demorará a reconhecer a fotografia como expressão artística, porque a fotografia não se manifesta segundo o aspecto aceitável e reconciliado da arte: o estilo. A técnica, que é necessária a todas as artes, inclusive na fotografia, pode se encerrar em si mesma e é um pequeno passo que transformará a técnica em criação. E com essa criação a fotografia pode fazer o que faz todas as artes: mudar a nossa visão de mundo.

Seria a fotografia ao mesmo tempo técnica e arte? Ter-seia, em primeiro lugar, que reafirmar que a fotografia não está condenada ao realismo, ao ilusionismo visual. Em segundo lugar, é possível perceber que a fotografia não tem um intermediário entre o objeto e sua imagem, e o que muda é a maneira de ver a imagem. Para Lemagny, toda arte edifica um objeto que compete com o real, mas não é simplesmente o "esse foi, mas não era isso" que nos remete à fotografia, aí residiria sua dignidade, seu benefício, mas não a distingue radicalmente de outras artes.

Colocando a fotografia nua, ela nada mais é que um índice de manchas de preto e branco ou cores. A foto é o resultado de um trabalho. E esse trabalho se resume ao sentido e à forma. Mas na fotografia a forma não é mais do que a remissão à outra forma. Porém, a fotografia pode ser de extrema nitidez, mas as formas jamais estarão totalmente presentes. E na senda dessas formas é que entra o imaginário da fotografia, aquilo que seria conflituoso com a definição da fotografia

EM TESE

BELO HORIZONTE

v. 19

N. 3

SET.-DEz. 2013 AUAD. A Sombra e a Crítica: fotografia, literatura, cinema

p. $94-108$

\section{Crítica Literária, outras Artes e Mídias}


7. LEMAGNY. La Sombra y el Tiempo, p. 76. [tradução livre de minha autoria]. por seu realismo. A fotografia, para o teórico francês, é do campo do imaginário.

Dessa forma, a fotografia não se define por seu ilusionismo visual, mas, sim, por sua realização, seus valores táteis, assim como as outras artes plásticas. A pintura e a escultura não querem ser mais do que outros objetos do mundo, nos remetendo ao real, ao passo que a fotografia nos leva ao rea evocando-o, como na poesia. E, por fim, o suporte da fotografia, a gelatina, que nunca será como uma peça de mármore. Isso permite que a fotografia herde toda a parte abandonada do sonho, sendo relacionada tanto com sua falta de precisão formal quanto com a incerteza de seus significados:

Que o imaginário seja o próprio da expressão fotográfica não se justifica em seu nível 'macro' de seu suposto realismo, e sim em seu nível 'micro' dessa enganosa nitidez de linhas e de superfície que não há mais do que remeter a uma suavidade fundamental da matéria que a constitui. É essa debilidade visual, interna à forma de toda foto, que é decisiva. ${ }^{7}$

Mas a fotografia sempre remetendo, sem cessar, a outra forma, a do real, faz com que a estrutura da criatividade fotográfica seja aquela da poesia, do eco. Não se trata de formas, mas de formas em eco.

No fim do seu texto o pensador francês termina remetendo a fotografia a uma pegada, a um vestígio: "No coração da fotografia está a poesia da pegada, do vestígio. Algo passou por aqui, deixou uma pegada, imaginem...”. ${ }^{8}$

Alguns pontos no texto de Lemagny nos parecem interessante para serem abordados em outras artes: a fotografia como arte fragmentada; a senda da forma onde nasceria o imaginário; a evocação do real e de outra forma; a fotografia como pegada. Abaixo, darei exemplos de outras artes em que aparecem esses fundamentos que Jean-Claude tenta se utilizar para definir a fotografia como arte.

\section{ALGO ACONTECEU ENTRE ALGO QUE NÃO ACONTECEU}

A marca da pegada, de um vestígio, aparece constantemente na literatura. Por exemplo, na distopia We, de Yevgeny Zemyatin, acompanhamos através do diário de D-503, o seu romance com I-330, uma mulher sensual. Esta o seduz e o leva a ter um romance "à moda antiga”. Na segunda vez em que o casal se encontra, lemos uma anotação interessante em seu diário:

Ela abriu a porta espelhada que foi ajustada em um lado do armário; ela esperou, olhando para mim por cima do ombro. Eu obedientemente saí. Mas eu mal tinha pisado no limiar, quando, de repente, eu precisava dela novamente pressionada contra o meu ombro - só por um segundo, no meu ombro, não mais.

Atirei-me de volta para o quarto - ela (provavelmente) estaria ainda abotoando seu uniforme em frente ao espelho.
8. LEMAGNY. La Sombra y el Tiempo, p. 76. [tradução livre de minha autoria].
EM TESE
BELO HORIZONTE
v. 19
N. 3
SET.-DEz. 2013 AUAD. A Sombra e a Crítica: fotografia, literatura, cinema
p. $94-108$

Crítica Literária, outras Artes e Mídias 
9. ZAMYATIN. We, p. 66. [tradução livre de minha autoria].
Eu corri e parei. O anel antigo da chave na porta do armário ainda está balançando - Eu vejo isso claramente - mas I-330 não está lá. Ela não poderia ter ido para nenhum lugar - só havia uma maneira de sair da sala - mas, no entanto, ela não estava lá. Eu saqueei tudo, eu até abri o armário e senti os vestidos antigos coloridos lá: ninguém ...9

D-503 tinha certeza do que iria ver. Tinha voltado ao quarto que acabara de sair para tentar um último momento de encontro, de um abraço reconfortante - nem que por um segundo. I-330 não estava mais no quarto. Ele se perde em pensamentos do que realmente vivera, do que realmente via ao lado da mulher amada. Uma tênue linha entre a imagem da memória e a imagem que de repente revê, agora, vazia de significado.

Zemyatin, ao construir seu livro em forma do diário de D-503, faz com que o leitor do texto não tenha também certeza se o narrado coincide com o fato. Nosso único suporte seria confiar nas palavras reproduzidas por D-503, mas palavras que nem o próprio narrador acredita. We é um livro que joga com todo um vestígio de uma narração e dos fatos. O narrador não pode nos confirmar o fato, também não podemos confiar no narrador. O texto, uma ficção científica, que se passa no futuro, não é mais do que um vestígio, uma pegada, do que aconteceu, do que aconteceria.

São muitos os filmes que nos articula com esse jogo de uma pegada, de apenas uma marca que nos leva a seguir toda a história. Em filmes como The Haunting de Robert Wise, como O Terceiro Homem, de Carol Reed, como Tubarão de Steven Spilberg, como Sátántangó de Bela Tarr, como em $O$ Bebê de Rosemary de Roman Polanski, como A Aventura de Michelangelo Antonioni, ou Les Yeux Sans Visage de Georges Franju - só para citar alguns - os cineastas utilizam uma construção semelhante para manter o suspense da trama: não mostram o rosto do mistério, o tempo todo escondido, levando o espectador a querer ver o que não pode ser mostrado ainda, a duvidar de tudo que vê. O que sustenta a trama é o não visto, aquilo que ainda poderá ser encontrado.

Essas marcas deixadas obviamente para a criação do suspense talvez sejam um pouco menos interessante na nossa comparação entre cinema e fotografia do como acontece em Punishment Park de Peter Watkins.

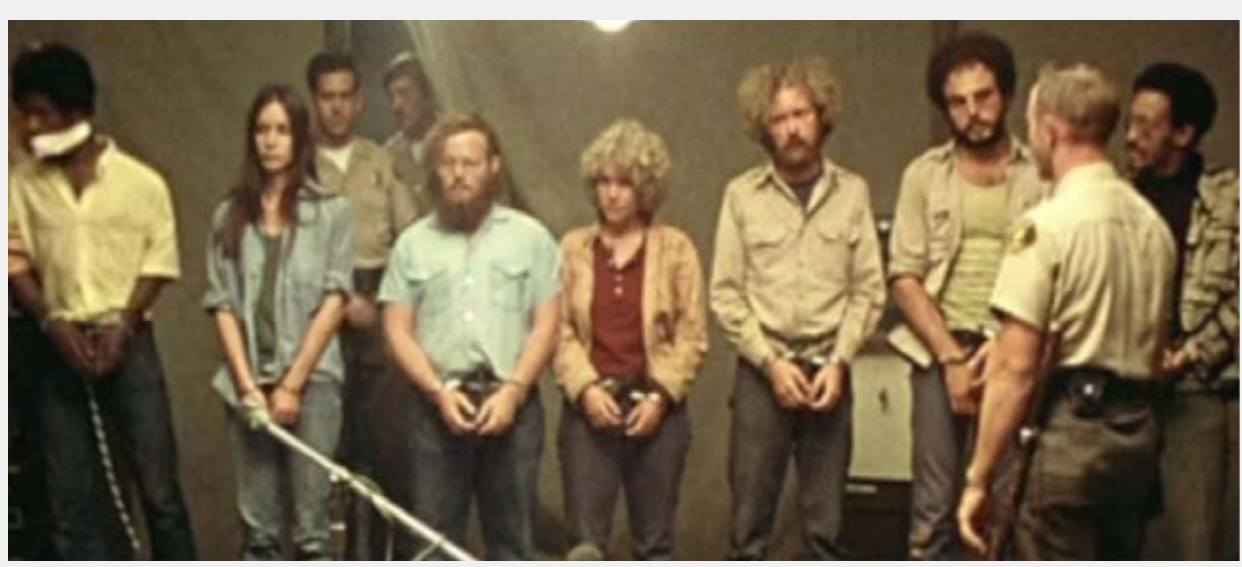

(E) 
Trata-se de um filme construído à maneira de um cinema-direto - estilo de documentário cinematográfico que se empenha em captar, através de diversas técnicas, a realidade tal como ela é - com "falsos" atores e história. No filme, acompanhamos dois enredos. No primeiro, temos jovens sendo julgados como subversivos, que, ao serem condenados, podem escolher a prisão ou o punishment park. No segundo enredo, vemos a execução da punição: os jovens são obrigados a correr por 36 horas até chegar a uma bandeira dos Estados Unidos da América com policiais atrás deles que podem inclusive matá-los.

O que impressiona no filme de Watkins não é só o estilo à la documentário. Filmes que se utilizam de tal efeito existem aos montes até na esfera mais comercial do cinema, como Borat, de Larry Charles, ou This Is Spinal Tap, de Rob Reiner. Watkins reúne jovens que realmente eram ativistas e subversivos na América na década de 70 e os "julga". Esse julgamento acontece em um tribunal especial e de exceção - que poderia acontecer naquele país - e a condenação também pode ser excepcional. Esses jovens "reais" - estão na tênue linha do que é fato e do que é ficção - são submetidos a um julgamento "irreal" - já que o julgamento de fato não acontecia, mas que poderia acontecer.

Esse regime e condenação de exceção, que nos anos 1970 poderiam parecer distantes, para nós fazem mais sentido hoje.
O que Watkins nos mostra em seu falso documentário é algo relativamente próximo ao que acontece em Guantánamo. Há algo de falso em Punishment Park, mas também há muito de real. Tal como acontecia na fotografia há essa evocação do real, a evocação de uma outra forma. Vemos os jovens subversivos, ouvimos seus discursos, vemos sua condenação e sua pena, vemos suas mortes, vemos em um filme de ficção, mas que poderia ser real, e que ao menos aponta para traços de realidade.

Outro filme que também aparece quase como um falso documentário é o radical Emperor Tomato Ketchup de Shûji Terayama. Quase, porque apenas alguns aspectos são mantidos pelo diretor do filme. O mais marcante deles é narração em off que descreve a dominação do mundo por crianças. O filme começa com a seguinte narração: "Nós fazemos a alegria e a glória do nosso coração para contemplar a prosperidade nacional e a alegria das crianças. Nós desprezamos nossa linhagem imperial. Esperamos manter a prosperidade do Estado em conjunto com os nossos amados filhos”. Mas a despeito de certas características documentais do filme, a imagem é que chama mais a atenção: 


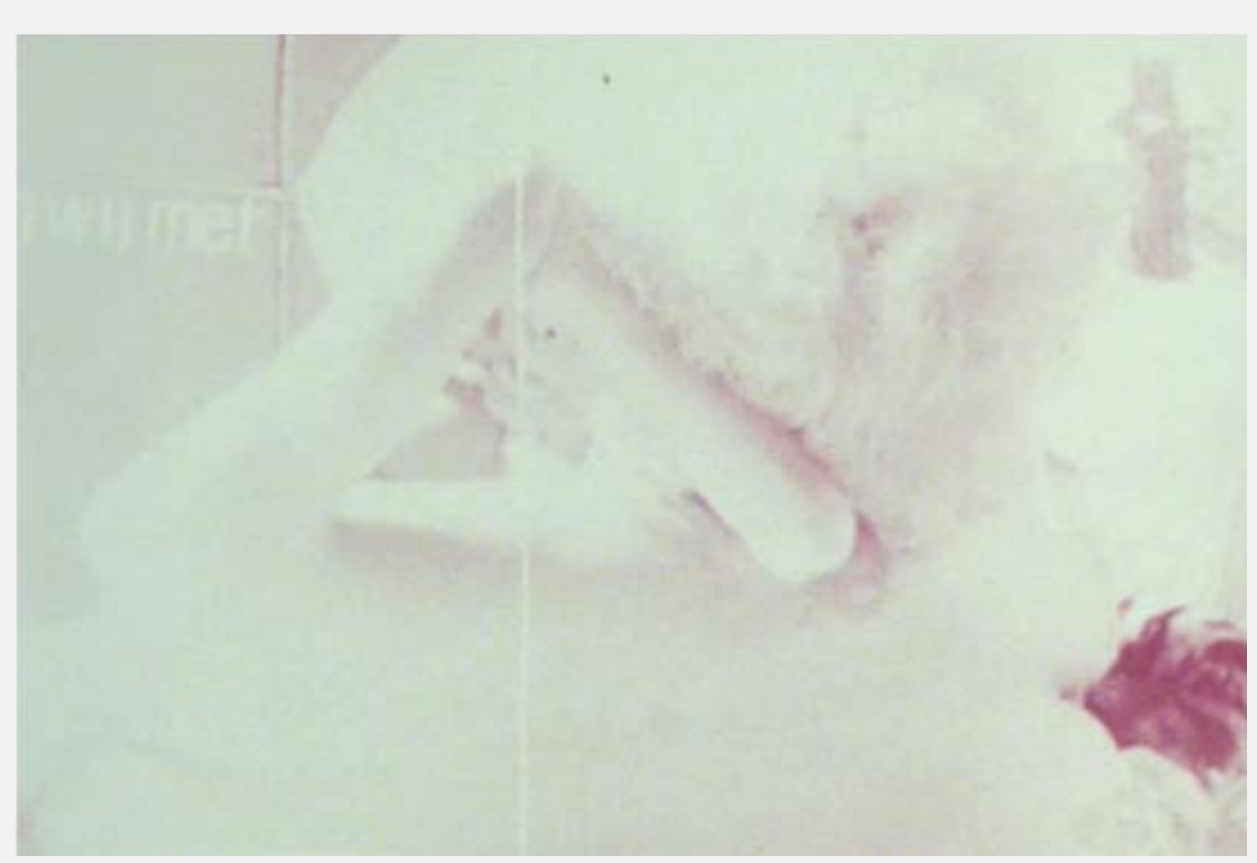

O filme é uma mistura anarquista de crianças, samurais, teatro Nô, sexo, fantasia e profanação. A senda da forma que Lemagny remetia à fotografia também aparece no cinema. São os traços muitas vezes vagos que vemos na imagem cinematográfica feita por Terayama. Algumas vezes, como na imagem acima, há uma espécie de borrão, em que é difícil definir os contornos da imagem. Em outros casos a imagem está aparentemente bem nítida, como é possível perceber na imagem abaixo, mas os contornos, aparentemente mais sólidos, são para não dar certeza à imagem mas a incerteza do que está acontecendo.

Aos olhos de alguns espectadores, o que acontece é um filme bizarro e pedófilo. A outros olhos é perceptível a revolta das
BELO HORIZONTE
N. 3

SET.-DEZ. 2013 crianças em relação aos seus pais, as meninas cantando "quando eu crescer e me tornar prostituta...", e é possível ver ao mesmo tempo a inocência e a destruição, brutalidade e beleza, vida e morte. O mistério desse filme não é construído no que não é mostrado, mas, justamente, no que é mostrado - com contornos bem ou mal definidos. É no que é mostrado que nasce uma falta. Nas imagens desfocadas, com contornos mal definidos, vemos tudo acontecer, mas sempre em falta, em uma senda, em uma abertura. As cenas independentes uma das outras acentuam a destruição da trama, e somos jogados em um perigoso jogo de inter-relações sem aparente explicação. Não é apenas em uma imagem independente que essa senda das formas, dos contornos, é construída. A abolição de demarcações acontece na forma total do filme, em suas raisons d'être.

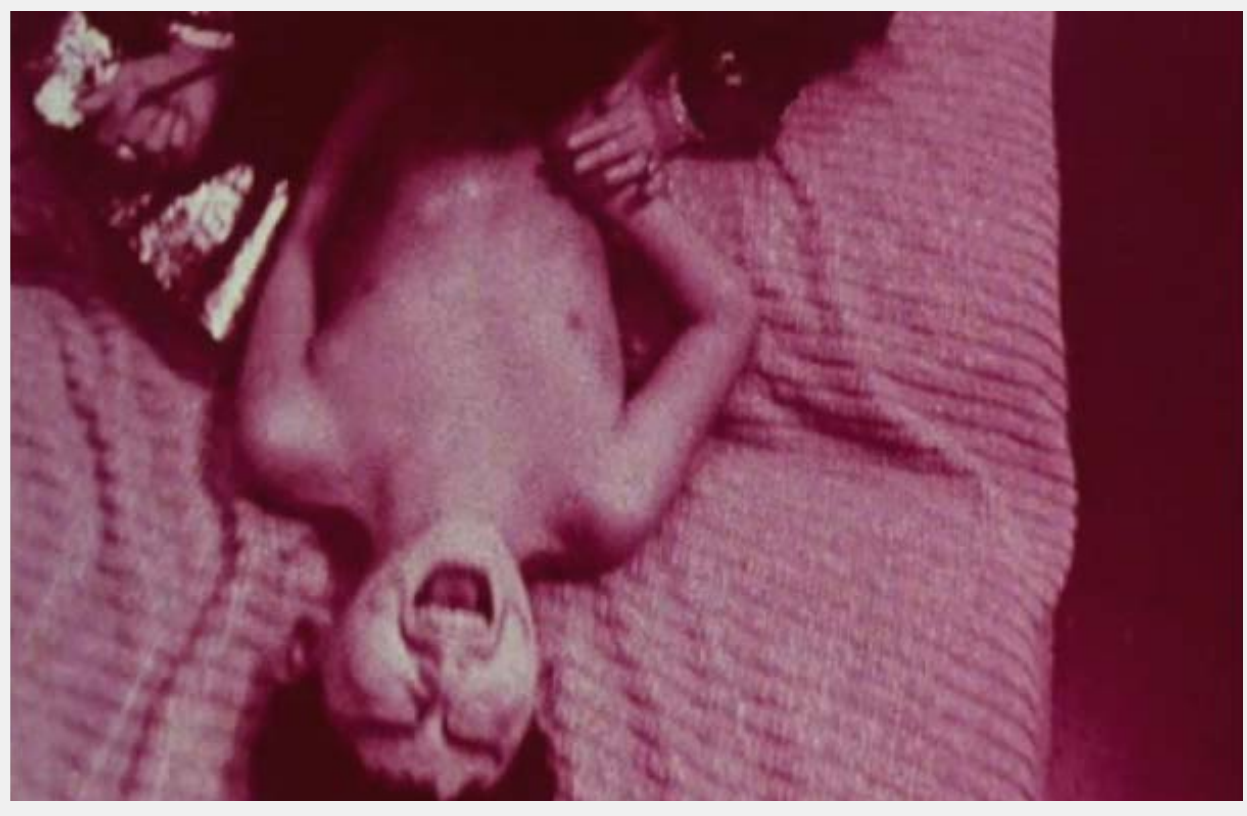

\section{Crítica Literária, outras Artes e Midias}


Como acontecem abolições de marcações, de fronteiras, a lógica de que a fotografia é uma arte específica - como primeiro aponta e depois refuta Lemagny - por ser um processo artístico fragmentado também é facilmente questionável. Cito, como exemplo, a novela gráfica $A$ História do Nome Harvey Pekar, escrito por Harvey Pekar e desenhada por Robert Crumb.

Os quadrinhos, e mais especificamente graphic novels, ainda encontram desafios para serem definidos como arte. Se Lemagny acha que a fotografia tem um espaço difícil ainda a ser conquistado, os quadrinhos parecem ter um caminho ainda mais duro a percorrer. É importante salientar que $L a$ Sombra y el Tiempo é um texto escrito já há algum tempo. Se hoje a fotografia é muito mais aceita, incluindo aí espaço considerável em museus e exposições, não é possível dizer o mesmo dos quadrinhos.

Mas o curioso dessa constatação é que o texto de Lemagny ilumina os pensamentos sobre essa arte ainda bastarda. Os quadrinhos, tal como a fotografia, em muitos casos não é realizado somente por uma mão. É o que pode ser verificado no exemplo escolhido para ilustrar: Harvey Pekar escreve e Robert Crumb ilustra.

Nessa história ver-se-á um homem explicar a origem do seu nome e sua estranheza em relação a ter outra pessoa com o nome Harvey Pekar no catálogo telefônico. Depois de elucubrar a respeito do nome próprio, o personagem desenhado se pergunta: "Quem é Harvey Pekar?" e posteriormente há um quadrinho vazio de falas. Quem é o artista?

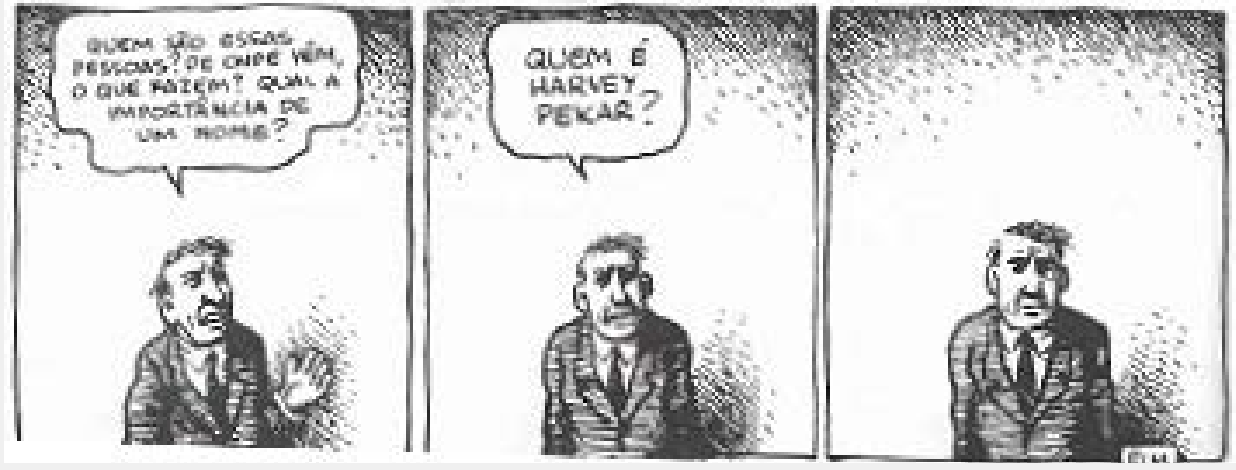

Arte ainda construída fragmentadamente, arte em que as linhas muitas vezes não são utilizadas para criar a definição da imagem, raramente há um desenho em que a imagem se propõe como realista. Arte que ainda se pergunta e se questiona, se autorreflete constantemente. Os quadrinhos parecem ainda mais próximos da fotografia em alguns aspectos do que o cinema ou a literatura. Nem mesmo as palavras são totalmente legíveis como na figura acima. Em Swallow me Whole de Nate Powell muitos dos diálogos são não mais do que um rastro, um rabisco, um borrão, um barulho que se ouvira ao longe.

Dessa forma, é possível perceber que a fotografia não está sozinha. Muitos aspectos que Lemagny atribui à fotografia podem ser encontrados em outras formas artísticas. Tentarei

\section{Crítica Literária, outras Artes e Mídias}


encontrar a motivação de delimitar a fotografia como arte e como essas delimitações são quase impossíveis: sempre há de surgir pontos comuns em todas as artes.

\section{ALGO ACONTECE ENTRE ALGO QUE NÃO ACONTECE}

Em muitas teorias que tratam a respeito das relações inter-semióticas, a comparação entre as artes é muito mais pela falta do que pela simples diferença. Ter-se-ia, no cinema, a imagem em movimento, na fotografia não, por exemplo Quando um teórico parece tentar especificar o objeto estudado - cinema, literatura, videogames - essa prática da falta é ainda mais positivada.

Lev Kuleshov, em The Art of Cinema, tenta definir o cinema pela montagem.

Ainda assim, quando começamos a analisar a figura cinematográfica, era muito difícil para nós determinar $o$ que emergia como o seu material, como esse material era organizado, o que é integral, impressões básicas - fazendo significado do cinema o que faz do cinema diferente de outras formas de performance ou de outras artes. Mas para nós era quase evidente que o cinema tem seus próprios meios de influenciar seus espectadores, desde que o efeito do cinema nos espectadores é radicalmente diferente do efeito de outros entretenimentos e espetáculos. ${ }^{10}$ p. 3. [tradução livre de minha autoria].
O cinema teria uma característica que outras artes e entretenimentos não possuem: a montagem. Jackbson, Pudovkin, entre outros, corroboram essa opinião. Porém, Eisenstein entra em cena colocando em xeque essa questão, mostrando em A Forma do Filme como Griffith tomou emprestado de Charles Dickens os procedimentos da montagem ${ }^{11}$. Ou seja, a implicação de falta que o cinema imporia na literatura não procede inteiramente.

Victor Shklovsky, em seu livro Literature and Cinematography tentou realizar um método diferente para definir campos artísticos. Nos primeiros capítulos do livro, ele demarca: música, pintura, escultura, literatura. O cinema entraria em um campo de interseção com a literatura. Mas ao tentar encontrar o que seria comum ao cinema e à literatura, acaba se apoiando muito mais nas especificidades que uma arte tem e a outra não. Afirmava ele que "um novo material precisa de uma nova forma" ${ }^{\prime 2}$, e essa nova forma seria o que falta ao outro. A investigação de Shklovsky passa pelo o que o cinema não pôde tomar emprestado da literatura e depois apenas inverte esse processo, o que a literatura não poderia tomar emprestado do cinema: "primeiramente, a literatura dominou sobre aparatos cinematográficos" ${ }^{13}$, posteriormente o cinema começava a influenciar a literatura. Então, Shklovsky acreditava que a literatura se transformaria em "uma esfera puramente linguística”" ${ }^{14}$, para se manter independente do
11. Cf. Eisenstein. A Forma do Filme. Para uma discussão mais ampla do assunto recomendo ainda o livro de César Guimarães, Imagem da Memória: entre o legível e o visível.

12. SHKLOVSKY. Literature and Cinematography, p. 40. [tradução livre de minha autoria].

13. SHKLOVSKY. Literature and Cinematography, p. 73. [tradução livre de minha autoria].

14. SHKLOVSKY. Literature and Cinematography, p. 73. [tradução livre de minha autoria].

\begin{tabular}{|c|c|c|c|c|c|c|}
\hline EM TESE & BELO HORIZONTE & v. 19 & N. 3 & SET.-DEZ. 2013 & AUAD. A Sombra e a Crítica: fotografia, literatura, cinema & \\
\hline
\end{tabular}

Crítica Literária, outras Artes e Mídias 
15. COMOLLI. Ver e Poder, p. 9-10 cinema. Dessa forma, faltaria ao cinema essa esfera puramente linguística que a literatura poderia oferecer. Por outro lado, é sabido que a união de som, imagem e texto do cinema também está em uma esfera linguística.

Ora, não é apenas nos primórdios do estudo cinematográfico e literário como ciência que a tentativa de definição de arte acontece. Ela continua aparecendo, apenas transformada, como acontece, por exemplo, no prefácio de Ver e Poder de Jean-Louis Comolli:

$\mathrm{Na}$ era dos clips, dos videogames, da publicidade, dos reality shows, o que temos a fazer em relação ao cinema? [...] Se somos espectadores é porque estamos engajados em uma prática do cinema e não somos apenas sujeitos do espetáculo. [...] O cinema - e não a televisão - que mostra quais são os limites do poder de ver ${ }^{15}$.

É no cinema, e não em outros sistemas semióticos, que, para Comolli, o espectador ainda não é um sujeito passivo dos "ataques" imagéticos. Comolli não coloca outras artes especificamente em questão, mas também defende apenas o cinema como a fuga de um mundo que nos torna anestesiados de tanta informação. Comolli quer nos dizer que o cinema é capaz e as outras artes não ao omitir tantas outras formas em que o espectador também estaria engajado em uma prática? Quando vemos uma escultura, uma pintura, uma fotografia, quando lemos um livro de poesia ou um romance, somos passivos da informação ou somos um consumidor "engajado"? O crítico de cinema francês parece pecar pela supervalorização do cinema ao omitir outros possíveis sistemas semióticos.

Em comparações realizadas entre o cinema e a literatura essas delimitações se tornam talvez um pouco mais polêmicas. Sabe-se que o cinema, ao menos nos seus primórdios, é formado por fotografias em movimento. As imagens na película, registradas uma a uma, quando projetadas numa tela em uma velocidade de vinte e quatro quadros por segundo, criam a sensação ou a ilusão de movimento. Por isso, ter-se-ia um acontecimento curioso: se antes o realismo era denotado à fotografia, quando do surgimento do cinema, ele é denotado a este por seu poder de recriação do desenvolvimento temporal da imagem, "capaz de reproduzir, não só mais uma propriedade do mundo visível, mas justamente uma propriedade essencial à sua natureza - o movimento" 16 O que se vê no cinema é a ilusão de movimento que advém da reprodução rápida de fotografias em sequência.

André Bazin, em seu texto Ontologia da Imagem Fotográfica, coloca a fotografia como o maior êxito das artes plásticas. A fotografia teria a capacidade de destituir da pintura a obsessão de recriar a realidade: "entre o objeto inicial e sua representação nada se impõe, a não ser um outro objeto"17, diz
16. XAVIER. O Discurso Cinematográfico, p. 18.

17. BAZIN. Ontologia da Imagem Fotográfica, p. 125.
EM TESE

BELO HORIZONTE

v. 19

N. 3

SET.-DEZ. 2013

AUAD. A Sombra e a Crítica: fotografia, literatura, cinema

p. $94-108$

\section{Crítica Literária, outras Artes e Midias}


18. BAZIN. Ontologia da Imagem Fotográfica, p. 126.

19. BAZIN. Ontologia da Imagem Fotográfica, p. 128
Bazin, dando à objetiva da câmera uma força que os pintores realistas não tinham. O cinema, por sua vez, "vem a ser a consecução no tempo da imagem fotográfica" 18 , justamente porque as imagens ali representadas têm a capacidade de também apresentar a duração.

Ainda segundo Bazin, "a fotografia nos permite, por um lado, admirar em sua reprodução o original que os nossos olhos não teriam sabido amar [...]. Por outro lado, o cinema é uma linguagem"19. A fotografia aparece como um fixador do tempo da realidade, aquele eterno momento cravado em um instante de realidade. O cinema, como uma linguagem, é desenvolvido com uma sintaxe e uma semântica, algo a ser decodificado pelo espectador do filme, a ser interpretado com a junção, ainda, da duração - curioso apontar que Bazin liga o cinema à linguagem, fato que Shklovsky parecia negar em seus estudos.

Outro que estabelece uma diferenciação entre cinema e fotografia é Roland Barthes. Em seu texto Retórica da Imagem a diferença central da fotografia para o cinema é que as fotografias teriam um efeito de "ter estado aqui" e o cinema de "estar aqui". A fotografia é tida como um elemento mecânico, tendo por isso a garantia de objetividade - o elemen to humano, para Barthes, é apenas conotativo. A fotografia não é como uma cópia, ou mesmo uma cópia mal realizada, como afirmam os platônicos. Barthes afirma:
A fotografia instaura, na verdade, não uma consciência do estar aqui do objeto [...], mas a consciência do ter estado aqui. Trata-se pois de uma nova categoria de espaço-tempo: local-imediata e temporal-anterior, na fotografia há uma conjunção ilógica entre o aqui e o antigamente. [...] Se pode compreender plenamente a irrealidade real da fotografia; sua irrealidade a irrealidade do aqui, pois a fotografia nunca é vivida como uma ilusão, não é absolutamente uma presença, e é necessário aceitar o caráter mágico da imagem fotográfica; sua realidade é a de ter estado aqui, pois há, em toda fotografia, a evidência sempre estarrecedora do isto aconteceu assim: temos, então, [.. uma realidade da qual estamos protegidos. [...] Poderíamos, assim, estabelecer, entre o cinema e a fotografia, não uma simples diferença de grau, mas uma oposição radical: o cinema não seria fotografia animada: nele o ter estado aqui desapareceria, substituído por um estar aqui do objeto; isto explicaria a existência de uma história do cinema, sem uma verdadeira ruptura com as artes anteriores da ficção, enquanto a fotografia, de uma certa forma, afasta-se da história. ${ }^{20}$

É possível constatar, em Barthes, alguns pontos curiosos pra essa discussão. A irrealidade real da fotografia, a sensação de um limite entre o aqui e o antigamente, esse loca onde a fotografia insiste em se inscrever, num limite, em um borrão, em uma indefinição de lugar ou formas.
EM TESE
BELO HORIZONTE
v. 19
N. 3
SET.-DEz. 2013 AUAD. A Sombra e a Crítica: fotografia, literatura, cinema
P. 94-108

Critica Literária, outras Artes e Mídias 
Outro ponto importante para a elaboração aqui proposta é a noção de que a fotografia afasta-se da história enquanto o cinema se inscreveria na história da arte geral - e não chega a citar, mas provavelmente acredita, que o cinema tem também a sua própria história, a história do cinema. Nesse ponto, Barthes entra em um quase conflito com Lemagny. Este insiste que para a fotografia ser arte é necessário que ela tenha uma história própria. É possível ver aqui certas diferenciações entre cinema e fotografia - apesar de usarem até certo ponto um mesmo material.

Barthes, diferentemente de Lemagny, não tenta ser tão pontual em suas discussões. O autor de Retórica da Imagem, semiótico, parece entender o problema que Lemagny e outros tentam resolver e aponta outra solução: os limites entre as artes, tal como a fotografia, é uma senda e não mais que um borrão, muito mais zonas de interseção do que muro de fronteira - claro que os índices semióticos das diversas artes se diferem em alguns pontos, mas em muitos outros são comuns. E, ademais, as teorias da arte em geral são feitas em fragmentos e acabam construindo a sua própria história. E essas teorias também são não mais do que um recorte do mundo, uma evocação do real - a arte - transformado.

Lemagny imbuído mais de uma motivação de filosofia estética - buscando o belo na fotografia - do que de uma motivação de um positivismo científico - em que é necessário definir o objeto para nascer uma ciência desse objeto - parece, por um lado, nos mostrar mais das teorias da arte do que da fotografia propriamente dita. Nesse sentido, a teoria seria teoria porque também é metateoria?

\section{EU E MINHA SOMBRA}

No belíssimo ensaio Me and My Shadow, Jane Tompkins afirma que nos trabalhos acadêmicos existem duas vozes, uma pessoal e um crítica, sendo a primeira sempre sufocada. A crítica norteamericana defende a voz pessoal: "[A crítica] seria sempre, de alguma forma, uma crônica das minhas horas e dias. Falaria com uma voz que pode falar de tudo, chegaria a um leitor como eu e me tocaria onde eu quero ser tocada"21.

Tompkins identifica no pós-estruturalismo uma saída para a sujeição do discurso científico, porque nessas teorias o mundo não é mais do que a maneira que se pensa sobre ele, não tendo assim o privilégio da verdade. A verdade seria sempre uma construção. Mesmo encontrando no pós-estruturalismo essa saída, ela ainda percebe em seus autores um problema de efeito autoritário: Felix Guatarri seria um exemplo de uma linguagem alienada e impessoal; Harold Bloom é chamado de "cósmico"; o problema em Michel Foucault é que ele falaria o tempo todo em "nós" em um lugar em que o "eu" não é apresentado. Tompkins acredita que é possível fazer teoria unindo essas duas vozes, a pessoas e a crítica,
21. TOMPIKINS. Me and My Shadow, p. 2134. [tradução livre de minha autoria]. 
22. KOSSOY. Os Tempos da Fotografia, p. 142. como se formassem um espaço de interseção, uma fronteira que pareceria muito mais um borrão. A crítica, dessa forma, daria espaço à sombra - à voz pessoal - que Tompkins defende que também deveria entrar no discurso.

Boris Kossoy afirma, a respeito das fotografias, que "a realidade das imagens é a realidade da sombra, sem carne, sem sangue... A realidade das imagens é a da aparência do duplo, dos corpos possuídos ou tomados do real" ${ }^{\prime 2}$. A crítica também não seria a realidade da sombra? A realidade daquele discurso nascido em um determinado espaço de tempo com experiências pessoais e concretas? A critica, nesse sentido, parece ser essa aparência do duplo.

Dessa forma, em alguns casos, o trabalho crítico poderia parecer como uma fotografia. Logo abaixo, é possível ver uma foto de Joel Peter-Watking intitulada Los Angeles Death Uma imagem desfocada centra a atenção na foto. Olhamo bastante tempo para a foto. Não há realmente ninguém morto, ninguém morrendo. Uma mulher em meio a um arbusto carros, casas, poste de luz. Umas manchas na foto. Mas não há uma morte. A morte está onde não a vemos, está de algum modo no disforme do foco, nas manchas da fotografia. A crítica, a senda, o disforme, a fragmentação, a fotografia.

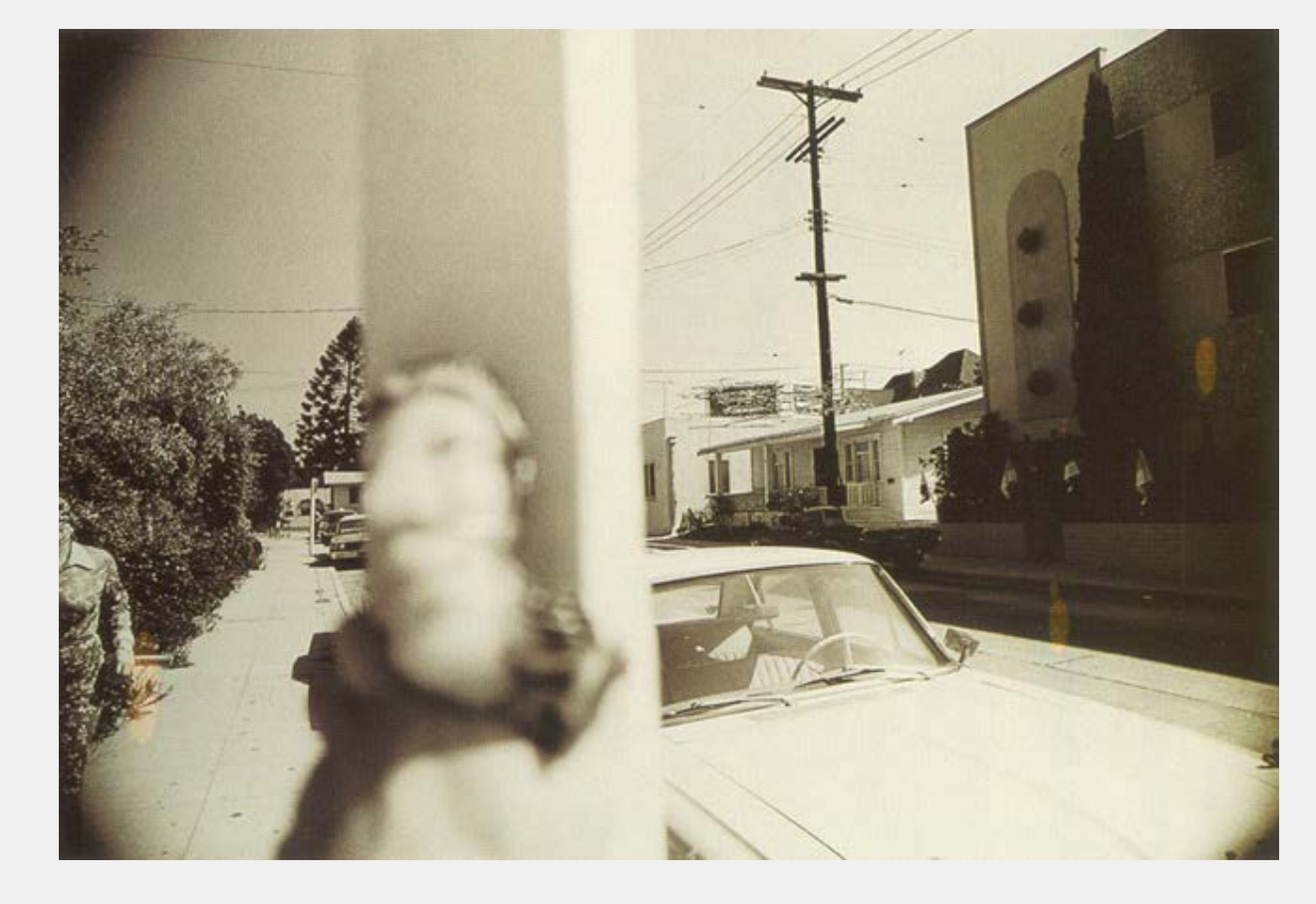

\section{REFERÊNCIAS}

BARTHES, Roland. A Retórica da Imagem. In: O Óbvio e o Obtuso: Ensaios Críticos III. Trad.: Léa Novaes. Rio De Janeiro: Nova Fronteira, 1990.

BAZIN, André. Ontologia da Imagem Fotográfica. Trad.: Hugo Sérgio Franco. In: XAVIER, Ismail. A experiência do cinema. São Paulo: Graal, 2008.

COMOLLI, Jean-Louis. Ver e Poder. Trad.: Augustin de Tugny; Oswaldo Teixeira; Ruben Caixeta. Belo Horizonte: UFMG, 2008.

EISENSTEIN, Sergei. A Forma do Filme. Trad. Teresa Ottoni. Rio de Janeiro: Jorge Zahar Editor, 2002. 
KOSSOY, Boris. Os Tempos da Fotografia. Cotia: Ateliê Editorial,

2007

KULESHOV, Lev. Art of the Cinema. In: Kuleshov on Film: writings of Lev Kuleshov. Los Angeles: University of California Press, 1974

LEMAGNY, Jean-Claude. La Sombra y el Tiempo. Buenos Aires: Biblioteca de La Mirada, 2008.

SHKLOVSKY, Viktor. Literature and Cinematography. Londres: Dalkey Archive, 2008.

TOMPKINS, Jane. Me And My Shadow. In: LEITCH, Vicent B. (Org.) The Norton Anthology of Theory and Criticism. Nova lorque: Norton, 2001.

XAVIER, Ismail. O discurso cinematográfico: a opacidade e a transparência. São Paulo: Paz e Terra, 2005

ZAMYATIN, Yevgeny. We. Londres: Vintage Books, 2007.

\section{Crítica Literária, outras Artes e Mídias}

